\title{
Propuesta teórica para la sistematización, archivo y recuperación de los datos de los sitios Web de entidades del tercer sector: El caso Colombia - Cataluña'
}

\author{
Theoretical proposal of systematization, storage and retrieval \\ of data concerning Websites of third sector organizations: \\ the Colombian and the Catalan case
}

\author{
Santiago Tejedor CALVO2 (D) 0000-0002-5539-9800 \\ Laia Montoliu RIU2 (D) 0000-0001-7933-7009
}

\begin{abstract}
Resumen
El sitio Web es el principal espacio comunicativo online de las entidades del tercer sector, aun así no existe un patrón que facilite su almacenamiento para que las entidades puedan archivar y recuperar sus sitios Web, como tradicionalmente se llevaba a cabo con las publicaciones en papel. Este estudio presenta una propuesta para la sistematización, el archivo y la recuperación de los datos de los sitios Web de entidades del tercer sector. A partir de esta propuesta de sistematización el artículo expone el análisis comparativo de sitios Web de entidades de paz colombianas y catalanas. Para el estudio se utilizó una metodología mixta en base a entrevistas en profundidad y análisis de contenido. El testeo de la propuesta de análisis para sitios Web ha permitido comprobar que la Web se mantiene como el principal eje comunicativo de las entidades. Así, como que los aspectos propuestos permiten llevar a cabo un análisis global del sitio Web y dan respuesta a las condiciones de comunicación para el cambio y la transformación social indicadas por Gumucio Dragon, pertinentes para la muestra que se ha analizado.
\end{abstract}

Palabras clave: Comunicación. Internet. Medios Sociales. Sociedad Civil. Organización no gubernamental.

\begin{abstract}
Traditionally, the organizations have had an archive with their publications in paper. Now, the Website is the main online communicative outlet of third sector organizations, but yet there is no pattern to facilitate their collect and storage. This study presents a proposal for the systematization, archiving and retrieval of data of the Websites of third sector organizations. The article exposes the test of this proposal for the comparative analysis of Websites of Colombian and Catalan peace organizations. The object of study has been approached using mixed methodology: in-depth interviews and content analysis. The results of the test allowed us to verify that the Website remains the main communicative outlet of the organizations. Furthermore, as the proposed aspects allow to carry out an
\end{abstract}

\footnotetext{
1 Artículo basead en la disertación de tesis, titulada "El moviment per la pau 2.0. Anàlisi dels recursos comunicatius que ofereix Internet per al moviment per la pau. Espais de trobada entre Catalunya i Colòmbia". Universidad Autónoma de Barcelona, 2015.

2 Universidad Autónoma de Barcelona, Facultad de Comunicació, Departament de Periodisme i de Ciències de la Comunicació. Carrer de les Vinyes, 08193, Cerdanyola del Vallès, Barcelona, Espanya. Correspondencia para/Correspondence to: LM RIU. E-mail: <laiamontoliu@gmail.com>.

Apoio: Institut Català Internacional per la Pau (Beca pre-doctoral FI-ICIP).

Recebido el 11 del octobre del 2018 y aprobado el 21 del enero del 2019

Como citar este artículo/How to cite this article

Calvo, S.T.; Riu, L.M. Propuesta teórica para la sistematización, archivo y recuperación de los datos de los sitios Web de entidades del tercer sector: El caso Colombia - Cataluña. Transinformação, v.31, e180069, 2019. http://dx.doi.org/10.1590/2318-0889201931e180069
} 
overall analysis of the Website. Ultimately, respond to the conditions of communication for change and social transformation that are relevant for the third sector organizations.

Keywords: Communication. Internet. Social media. Civil Society. Nongovernamental Organization.

\section{Introducción}

Desde finales de los años noventa la red ha ido ganando peso en distintas esferas sociales y económicas de todo el mundo. Instituciones de todo tipo han tenido que digitalizarse, es decir adaptarse a la red. Más allá del cambio tecnológico, la digitalización ha conllevado la exigencia de aplicar en el seno de las organizaciones los valores de transparencia, gestión de la conversación y organización en red.

Paralelamente la ciudadanía ha ido generando sus espacios y formas de protesta en Internet, el ciberactivismo y el uso de la red como medio para facilitar las relaciones y la coordinación entre grupos afines. Por todo ello, las entidades del tercer sector también han tenido que adaptarse, para evitar quedarse al margen de este medio de comunicación social. En el argumentario del titular del Juzgado de lo Penal número de 16 de Madrid, Ricardo RodríguezFernández, al director de la Cadena SER, Daniel Anido, y al Jefe de Informativos, Rodolfo Irago, por revelación de secretos en publicar en la Web de la SER un listado de nombres de afiliados irregulares del PP a Villaviciosa de Odón: "La protección constitucional al derecho de la información se refiere a los medios de comunicación social (televisión, radio o prensa escrita) pero, debe matizarse, Internet no es un medio de comunicación social en sentido estricto, sino universal" (El País, 2009, s/p.). Adaptarse a la transparencia, la agilidad y la lógica de la red es uno de los principales retos que plantea Internet y la lógica 2.0 a entidades del tercer sector. Siendo la transparencia tanto un reto como uno de los principales valores para instituciones públicas como para las del sector no lucrativo (Balas, 2011; Peña-López, 2014; Rodriguez-Navas, 2014).

Para el tercer sector Internet ha abierto la posibilidad de posicionarse en la agenda pública sin tener que pasar por el filtro de los medios de comunicación convencionales (Linchuan Qiu, 2011). Tener sus altavoces en la red también ha supuesto la oportunidad para estas entidades de poder aplicar su visión de la comunicación a medios gestionados por ellos mismos. Es decir, experimentar nuevas rutinas y aplicar en sus espacios comunicativos lo que reivindican a medios de comunicación convencionales. Cómo llevar a cabo una comunicación horizontal, empática, participativa, inclusiva, que permita la reflexión y que incluya temas en la agenda que requieren de análisis y reflexión (Martín-Barbero, 2002; Gumucio Dragon, 2012; Cadavid Bringe, 2014).

En cuanto a los canales comunicativos, instituciones, como Organización no Gubernamental (ONG), tuvieron que hacer frente al reto de crear y mantener un sitio Web así como abrir el canal de comunicación directa con los usuarios a través del correo electrónico. Más adelante a partir del 2.0, con la irrupción de medios sociales como Facebook o Twitter, las instituciones tienen que conocer y distribuir su presencia y actividad en estos nuevos canales. Teniendo en cuenta que la centralización de la conversación en determinadas plataformas comerciales virtuales obliga a: asumir sus condiciones de uso y publicación; ceder los derechos de los contenidos a dichas plataformas, por lo tanto no beneficiarse del contenido que publican y perder el control sobre su distribución; no participar en la toma de decisiones sobre los propios medios (Fuchs, 2014); convivir en un mismo ecosistema comunicativo a distintos contextos culturales, económicos y sociales; y ser consciente de que la participación en los medios sociales facilita el seguimiento y el control gubernamental y comercial de la conversación ciudadana (Tilly; Wood, 2010; Uldam, 2017), lo que se puede denominar la monitorización del ágora.

Las más de dos décadas de presencia ininterrumpida de comunicación institucional de entidades del tercer sector en Internet ofrece la perspectiva necesaria para perseverar en su análisis. Por este motivo, esta investigación se propone profundizar en metodologías y herramientas que permitan el análisis, la comparación y la conservación y recuperación de los datos de los sitios Web de las entidades. Esta investigación pretende contribuir a la línea de investigación propuesta por Martín Barbero (2002) de acercamiento a los procesos comunicativos desde la perspectiva de los movimientos sociales. 
Para finalizar, la investigación se justifica tanto desde su proyección social y su implicación práctica, debido al interés que despiertan los resultados en el objeto, como desde la novedad, principalmente por su aportación metodológica.

\section{Antecedentes}

Esta investigación se suma a las publicadas en el ámbito de la comunicación en el tercer sector, comunicación para el cambio social, sobre comunicación por la paz y sobre social media y sobre sitios Web institucionales. Entre las investigaciones sobre comunicación del tercer sector destacan las enfocadas en el ámbito de la publicidad, las relaciones públicas y el márketing (Balas, 2011; González Álvarez, 2013). En cuanto a las que apuestan por una comunicación transformadora se centran en las ONG de Desarrollo (Cadavid Bringe, 2014). De las que analizan comunicación por la paz destacan las que analizan programas de organismos de comunicación por la paz de organizaciones (Fernández et al. 2011), las que sistematizan experiencias de construcción de paz desde la comunicación, especialmente en Colombia (Rodríguez; Gonzáles, 2007; Vega, 2011), y las que se centran en el periodismo de paz (Lynch, 2007). Sobre social media existen investigaciones que analizan cómo las entidades sin ánimo de lucro crean engagement en Twitter y Facebook (Thelwall; Cugelman, 2017) y sobre el activismo y la implicación en la vida política de usuarios de estas plataformas (Cabalin, 2014; Papa, 2017). Finalmente, los sitios Web institucionales han sido el eje de investigaciones alrededor de la participación ciudadana en instituciones (Giraldo Luque; Villegas Simón; Durán Becerra, 2017), la comunicación política de administraciones (FernándezFalero et al. 2017) la transparencia de organismos públicos (Moreno-Sardà; Rodríguez-Navas; Corcoy Rius, 2013; Rebolledo, Zamora-Medina, Rodríguez-Virgili, 2017) e incluso el posicionamiento de la publicidad en sitios Web de juegos para menores (Marti-Pellón; Craveiro, 2015).

Esta investigación, pues, viene a llenar el hueco metodológico para: la sistematización el análisis de los sitios Web de entidades del tercer sector; contribuir a mejorar las aspiraciones de las entidades en la red; aportar más elementos en el análisis de la comunicación de las entidades; $y$, dotar a las entidades de una herramienta adecuada y sencilla para el archivo de las versiones de su sitio Web.

Las siguientes preguntas son las que se formularon para iniciar la investigación: (a) ¿Cómo son los sitios Web de las entidades? ¿Han evolucionado?; (b) ¿Cómo podremos saber cómo eran y cómo han evolucionado?; (c) ¿Se archiva la presencia en la red como se archiva la comunicación en papel?

El objetivo de esta investigación es: Crear una herramienta/técnica/mecanismo para el almacenamiento, la sistematización y el análisis del principal canal comunicativo de las entidades: el sito Web.

Finalmente, se formularon las hipótesis: Internet juega un papel cada vez más relevante en la comunicación institucional de entidades del tercer sector $(\mathrm{H} 1)$; y, el sitio Web es la pieza clave en la comunicación digital de las entidades por este motivo es importante dotar a las entidades de una herramienta/técnica/mecanismo para facilitar el archivo de su sitio Web (H2).

\section{Procedimientos Metodológicos}

En este punto se detalla la propuesta metodológica para análisis global de un sitio Web. Para abordar el objeto de estudio se ha elegido una metodología mixta: entrevista en profundidad y análisis de contenido.

Con la entrevista en profundidad se ha podido conocer la experiencia concreta de los sujetos (Callejo, 2002) en la comunicación institucional de entidades. Para realizar las entrevistas se ha partido de un cuestionario semi-estructurado con un grupo de preguntas comunes y otro de preguntas específicas para cada sujeto.

Para el análisis de contenido del sitio Web se han tenido en cuenta dos puntos claves: en primer lugar como solventar la dificultad en el almacenamiento y la recuperación de los datos para investigaciones posteriores; y, en 
segundo, la descripción detallada de los aspectos a analizar para conseguir un abordaje global en el estudio de un sitio Web.

El análisis de contenido es una metodología habitual en la investigación en medios de comunicación (Noguera Vivo, 2010; Lovejoy; Waters; Saxton 2012; Costa; Pieiro-Otero, 2012) y las investigaciones sobre sitios Web no son una excepción. Para poder llevar a cabo una investigación basada en el análisis de contenido los datos documentales han de poder ser recuperados de forma que permitan ser analizados de forma clara, sistemática y cuantitativa (Berelson, 1971; Casasús, 1985; Bardin, 1986; Krippendorff, 1990).

Ante el auge de este tipo de investigaciones en sitios Web surge la duda de ¿cómo podrán ser reproducidas? Teniendo en cuenta la inexistencia de una hemeroteca o mediateca del ciberespacio, el almacenamiento y la recuperación de los datos es uno de los principales handicaps en las investigaciones centradas en el análisis de sitos Web.

Para dar respuesta a este hándicap durante la investigación se llevaron a cabo una serie de pruebas, para finalizar con un prototipo de recolección, almacenamiento y recuperación de datos ágil, visual y jerarquizador que facilita su análisis, conservación y reproducción. El modelo creado ad hoc para este caso es adaptable a sitios Web institucionales de otro tipo de organizaciones, como administraciones municipales o pequeñas y mediana empresas.

Antes de entrar en la descripción del modelo, hace falta mencionar dos de las principales herramientas que fueron probadas y descartadas: WaybackMachine y SiteSucker.

WaybackMachine es la única herramienta que se dedica a hacer un archivo regular de la world wide Web. Permite navegar a través de 310 mil millones de sitios Web archivados desde 1996 hasta hoy. Para acceder sólo hace falta indicar lo Uniform Resource Locator (URL) del sitio que se desea visitar en su navegador y elegir en un calendario la fecha a la que se quiere acceder. Es una herramienta muy interesante para ver la evolución de sitios Web, sobretodo los que tiene más tráfico. Pero no es suficientemente exhaustiva como para tener un archivo completo y adecuado de sitios concretos como los que forman la muestra de esta investigación. El sistema de almacenaje también presenta otro tipo de dificultades para la recuperación de datos, como la pérdida de las imágenes, enlaces rotos e incluso pérdida del código de diseño de los sitio.

SiteSucker es un programa informático que permite la descarga de sitios Web en un ordenador. El programa es sencillo y funcional. En una barra se indica la URL del sitio Web que se quiere descargar. El programa inicia la descarga desde la página inicial y traslada todo el sitio Web al disco duro manteniendo el orden de las carpetas. En cada caso la duración del proceso de descarga varia. Se desestimó su uso a causa de las dificultades. En concreto el ordenador se colapsó en repetidas ocasiones cuando la descarga del sitio Web sobrepasaba los 10GB y el programa necesita empezar cada descarga desde el inicio. Lo que hacía la tarea inabastable para realizar la descarga en un ordenador personal.

Una vez desestimadas las opciones anteriores, se optó por recopilar los datos a través de capturas de pantalla de las páginas iniciales de los sitios Web y todas las páginas enlazadas con esta página inicial. Lo que permitió sistematizar y organizar los datos para que sean analizados y recuperados cuando se desee.

La particularidad de los datos recolectados, imágenes, condiciona su codificación. Esta se ha llevado a cabo a través de la organización de las imágenes obtenidas en esquemas que emulan los enlaces y su jerarquía dentro del sitio Web. Las imágenes han sido tratadas con Photoshop (para unir distintas capturas, tantas como el scroll pedía, en una única imagen) y los esquemas se han diseñado con Illustrator. Ambos programas de Adobe (San José, California, Estados Unidos). Una vez establecidos los esquemas permite identificar áreas y subáreas de los sitios Web. La utilización de un esquema de este tipo ha permitido configurar una base de datos para poder procesarlos.

Una vez esclarecido el proceso de almacenamiento y recuperación de datos, se aborda el segundo punto clave de la metodología: la descripción detallada de los aspectos a analizar para conseguir un abordaje global en el estudio de un sitio Web. 
Para el abordaje global del análisis de sitios Web se consideran cinco aspectos: descriptivo, variedad de voces, interacción, contenido y temporales. Con estos cinco aspectos se pretende como los sitios Web de las entidades reúnen las condiciones de comunicación para el cambio y la transformación social señaladas por Gumucio Dragon (2012): participación y apropiación, adecuación cultural y lingüística, contenidos locales, uso de la tecnología apropiada y que se desarrollen en red. En lo siguiente cuadro (Cuadro 1) se muestran la descripción y los elementos de análisis de cada uno de estos aspectos.

Cuadro 1. Ficha de análisis sitio Web. Barcelona, Espanya (2015).

\begin{tabular}{|c|c|c|c|}
\hline Aspecto & Variable & Descripción / Objetivo & Elementos de análisis \\
\hline \multirow{9}{*}{ Descriptivo } & \multirow{9}{*}{ Tipo de sitio Web } & $\begin{array}{l}\text { Aspectos generales, identificación de tipos de contenido, } \\
\text { estructura y esquema de enlaces de la home. }\end{array}$ & Nombre del dominio \\
\hline & & & Objetivo de la página \\
\hline & & Conocer el espacio e identificar los elementos de análisis. & Diseño \\
\hline & & & Contenidos dinámicos y estáticos \\
\hline & & & Licencia de los contenidos \\
\hline & & & Idioma \\
\hline & & & Proveedor \\
\hline & & & Estructura de la home \\
\hline & & & Esquema de enlaces de la home \\
\hline \multirow{6}{*}{ Pluralidad de voces } & \multirow{6}{*}{ Voces identificadas } & Presencia, tipo y clase de voz (autor). & Actualidad \\
\hline & & & Agenda \\
\hline & & $\begin{array}{l}\text { Conocer la pluralidad de voces que ampara y amplifica la } \\
\text { entidad desde su Web. }\end{array}$ & Secciones \\
\hline & & & Banners \\
\hline & & & Créditos \\
\hline & & & Enlaces \\
\hline \multirow{10}{*}{ Interacción } & \multirow{4}{*}{ Con otras Webs } & Presencia y tipo de enlaces. & Menú \\
\hline & & & Secciones \\
\hline & & Conocer cómo se relaciona con el resto de la red. & Enlaces \\
\hline & & & Créditos \\
\hline & \multirow{4}{*}{ Con usuarios } & $\begin{array}{l}\text { Tipo de propuesta (contacto, participación, compartir } \\
\text { contenido...). }\end{array}$ & Redes Sociales \\
\hline & & $\begin{array}{l}\text { Forma de propuesta (correo electrónico, medios } \\
\text { sociales...). }\end{array}$ & RSS \\
\hline & & & Suscripción \\
\hline & & $\begin{array}{l}\text { Conocer qué posibilidades ofrece la web para fomentar } \\
\text { la participación. }\end{array}$ & Contacto \\
\hline & \multirow{2}{*}{$\begin{array}{l}\text { Integración de } \\
\text { elementos para la } \\
\text { interacción }\end{array}$} & Tipo de herramienta y de llamada a la acción. & Redes Sociales \\
\hline & & $\begin{array}{l}\text { Conocer las herramientas que se integran para vehicular } \\
\text { la participación. }\end{array}$ & Intranet \\
\hline \multirow{3}{*}{ Contenido } & \multirow{3}{*}{$\begin{array}{l}\text { Bloques temáticos } \\
\text { predominantes }\end{array}$} & Contenido sobre su fin, contenido sobre sí misma. & Secciones \\
\hline & & & Actualidad \\
\hline & & $\begin{array}{l}\text { Conocer las temáticas que interesan y que amplifican } \\
\text { desde la Web. }\end{array}$ & Agenda \\
\hline \multirow{3}{*}{ Temporal } & \multirow{3}{*}{ Vitalidad del sitio Web } & Publicaciones con periodicidad. & Actualidad \\
\hline & & Cambios relevantes. & Agenda \\
\hline & & Conocer la vitalidad de la Web. & Toda la Web (febrero - noviembre) \\
\hline
\end{tabular}

Fuente: Elaboración propia (2015). 
Para elaborar la muestra se han realizado entrevistas en profundidad a responsables de comunicación de organizaciones de paz y a expertos. Se han seleccionado las personas a entrevistar según los criterios de representatividad, profesionalidad, predisposición e interés. En concreto se han entrevistado responsables de comunicación de ocho entidades, cuatro colombianas (Fundación Ideas para la Paz, Verdad Abierta, Movimiento de Víctimas de Estado y Organización Nacional Indígena de Colombia) y cuatro catalanas (Institut Català Internacional per la Pau, FundiPau, Centre d'Estudis per la Pau Delàs y Taula Catalana per la Pau i els Drets Humans a Colòmbia). Además de siete expertos en comunicación de entidades, comunicación para el desarrollo y cambio social y social media.

En cuanto, la propuesta de análisis para sitios Web se ha testeado en una muestra formada por Webs de entidades de paz de Colombia y de Catalunya. Para elaborar la muestra intencionada se tuvieron en cuenta los siguientes criterios: que las Webs fueran gestionadas por actores representativos del movimiento; que existiera un equilibrio entre el número de sitios de colombianos y catalanes; se priorizo a entidades que trabajasen en ambos contextos; asegurar la presencia de entidades públicas y privadas; que las Webs seleccionadas correspondiera tanto a entidades que fueran muy activas en la red como poco activas; asegurar la presencia de organizaciones con estructuras y fines diversos, pero con una misma visión de la paz, desde la perspectiva de la paz positiva (Galtung, 2003). Se seleccionaron siete organizaciones colombianas y seis catalanas, de las que se han analizado 13 sitios Web (2.140 unidades de análisis). Los datos se recogieron en dos periodos: mayo y noviembre de 2012, lo que permitió comprobar los cambios que se habían producido en los sitios en seis meses (Tabla 1).

Tabla 1. Muestra análisis de contenido. Barcelona, Espanya (2012).

\begin{tabular}{|c|c|c|c|}
\hline Nombre & Tipo & Web & Unidad análisis \\
\hline 1. Institut Català Internacional Per la Pau & Cataluña - Institución Pública & http://icip.gencat.cat & 135 \\
\hline 2. FundiPau & Cataluña-ONG & http://www.fundipau.org & 313 \\
\hline 3. Universitat Internacional de la Pau & Cataluña - Entidad & http://www.universitatdelapau.org & 107 \\
\hline 4. Centre d'Estudis per la Pau JM Delàs & $\begin{array}{l}\text { Cataluña - Centro de } \\
\text { Investigación }\end{array}$ & http://www.centredelas.org & 224 \\
\hline 5. Escola de Cultura de Pau & Cataluña - Universidad & http://escolapau.uab.cat/index.php & 162 \\
\hline $\begin{array}{l}\text { 6. Taula Catalana per la Pau i els Drets } \\
\text { Humans a Colòmbia }\end{array}$ & Cataluña - Supraentidad & http://www.taulacolombia.org/index.html & 62 \\
\hline $\begin{array}{l}\text { 7. Movimiento Social de Mujeres Contra } \\
\text { la Guerra y por la Paz }\end{array}$ & Colombia - Supraentidad & http://www.mujerescontralaguerra.com & 70 \\
\hline 8. Colombianos y Colombianas por la paz & Colombia - Movimiento & $\begin{array}{l}\text { http://www.piedadcordiva.net/ } \\
\text { piedadparalapaz/index.php }\end{array}$ & 30 \\
\hline $\begin{array}{l}\text { 9. Movimiento de Víctimas de Crímenes } \\
\text { de Estado }\end{array}$ & Colombia - Supraentidad & http://www.movimientodevictimas.org & 296 \\
\hline $\begin{array}{l}\text { 10. Asamblea Permanente de la Sociedad } \\
\text { Civil por la Paz }\end{array}$ & Colombia - Proceso participativo & http://www.asambleaporlapaz.com & 115 \\
\hline $\begin{array}{l}\text { 11. Comunidad de Paz San José de } \\
\text { Apartadó }\end{array}$ & Colombia - Comunidad & http://www.cdpsanjose.org & 92 \\
\hline 12. Fundación Ideas para la Paz & $\begin{array}{l}\text { Colombia - Centro de } \\
\text { Investigación }\end{array}$ & http://www.ideaspaz.org/portal/index.php & 220 \\
\hline 13. International Peace Obsevatory & $\begin{array}{l}\text { Colombia (Cataluña, Italia) - } \\
\text { Movimiento }\end{array}$ & http://www.peaceobservatory.org/es & 315 \\
\hline Total & & 13 sitios Webs & 2.141 \\
\hline
\end{tabular}

Fuente: Elaboración propia (2012). 


\section{Resultados}

A raíz de la investigación todos las personas entrevistadas coinciden en considerar que el sitio Web es el principal espacio comunicativo de las entidades. Así, aunque las entidades han abierto otros canales comunicativos en la red, como perfiles en Facebook o Twitter, el sitio Web se mantiene como el eje de su comunicación. Los resultados se presentan estructurados a partir de los cinco aspectos analizados: descriptivo, pluralidad de voces, interacción, contenido y temporal.

En primer lugar del aspecto descriptivo destaca que en prácticamente todos los casos analizados se identifica que el principal dominio utilizado es el .org, por lo que desde el dominio del sitio Web se indica que se trata de una organización y que tiene un nombre propio, es decir contrata un servicio para que su nombre aparezca en su URL. Sólo se identifican dos URL que son un subdominio de una entidad mayor. Se trata de entidades que dependen de un organismo mayor (la Generalitat de Catalunya y la Universitat Autònoma de Barcelona). En todos los casos son Webs institucionales y públicas, con diseños en los que prima la verticalidad y constituidas por contenidos dinámicos y estáticos. Las Web también comparten la siguiente estructura:

1. Un marco de contenido principal, en el que se identifica una columna izquierda con las principales secciones de la Web, una parte central donde se publica la actualidad de la entidad y un espacio en la derecha que alberga por ejemplo los widgets de los perfiles a medios sociales.

2. Un marco superior con los logotipos de las entidades.

3. Un marco inferior que se destina a los créditos del sitio Web y de la entidad.

En segundo lugar en las páginas Web analizadas se amparan variedad de voces, tanto voces de personas como de instituciones. En concreto en el caso catalán prácticamente es igual la presencia de voces personas que de entidades, con una diferencia de menos de 1\% a favor de las personas. En cambio en el caso colombiano prácticamente tres de cada cuatro voces son de entidades (un 74\%).

Si se entra a analizar el tipo de voces que amplifica el sitio Web en prácticamente 8 de cada diez casos en ambos contextos se trata de la propia entidad (40\%) o de activistas (38\%), es decir tanto personas vinculadas a otras entidades, como ONG o defensores de los derechos humanos y de la paz. El restante $20 \%$ se distribuye entre administraciones públicas de distinto ámbito (9\%), normalmente como financiadoras de algún proyecto; investigación (5\%), que contempla a instituciones acadèmicas y profesorado; comunicación (4\%), tanto medios de comunicación social como periodistas y comunicadores; colabora (1\%), que incluye organizaciones y proyectos en los que la entidad colabora; y, otros (3\%), que contempla aquellos autores que no se corresponden en ninguna de las opciones anteriores (Figura 1).

En cuanto a la comparativa del tipo de voces entre ambos contextos la principal diferencia se encuentra en una mayor presencia de la administración pública y de voces vinculadas con la investigación en el caso catalán que en el colombiano. En ambos casos, destacan las voces que se vinculan con la propia entidad y las que se identifican como activistas, suponiendo el 86\% en Colombia y el 69\% en Cataluña.

En tercer lugar, la interacción aborda desde la relación de la Web con el resto de la red, desde las propuestas de interacción hacia los usuarios y a través de las herramientas que se ofrecen para fomentar la interacción.

Primero, en relación a los links cabe destacar que entre los enlaces identificados en las Webs sólo un 15\% de la muestra colombiana y un $23 \%$ de la catalana dirigen a un enlace externo, es decir dirige a una página fuera del sitio Web. Además, estos enlaces externos generalmente dirigen hacia perfiles en los medios sociales de las entidades analizadas.

Segundo, existen distintas opciones de interacción a los usuarios de la Web. La opción mayoritaria es la de compartir contenido. Es decir, se facilita en un $43 \%$ de los casos que los usuarios difundan contenido de la 


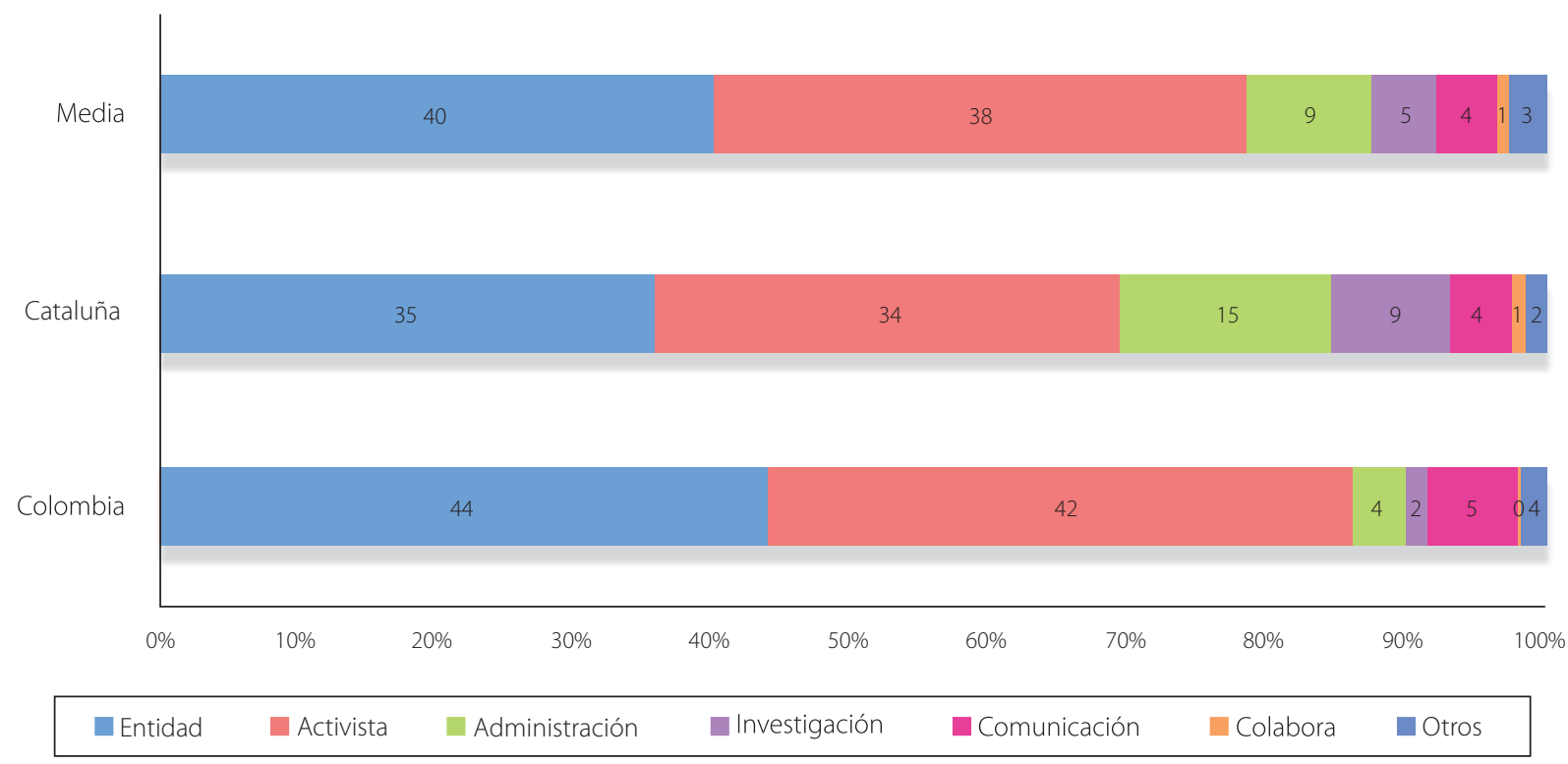

Figura 1. Tipo de voces por porcentaje.

Fuente: Elaboración propia (2015 con datos de 2012).

propia entidad por correo electrónico o a través de las redes sociales de los usuarios. También existen más opciones relacionadas con el contenido que propone la entidad: como suscribirse a las actualizaciones del sitio (18\%) o seguir los medios sociales de la entidad (6\%).

Como se observa en la Figura 2 opciones de participación (22\%) se incluyen opciones como escribir un comentario, entrar en la intranet, votar en una encuesta o participar en actividades fuera de Internet.

Tercero, cabe destacar que hay más presencia de elementos para la interacción en la muestra catalana (22\%) que en la colombiana (8\%). En el caso colombiano las herramientas usadas en un 56\% de los casos son creadas específicamente para el sitio Web, en cambio en el caso catalán se trata de widgets de medios sociales (86\%) de los casos. La principal modificación que se ha observado en los sitios Web analizadas ha sido la inclusión de widgets de medios sociales, como los que muestran las últimas actualizaciones en Twitter.

En cuarto lugar del análisis del contenido se desprende que la Web es el espacio en la red que se utiliza para describir la entidad, sus actividades y recoger sus publicaciones. En este sentido se puede acceder desde la Web a documentos como las memorias o las juntas de las entidades y a la actualidad y la agenda de la entidad.

Como muestra la Figura 3 en los sitios Web de ambos contexto predomina el bloque temático sobre movimiento por la paz, en el que se incluyen los contenidos que versan sobre la misma organización. Sobretodo es así en el caso catalán que suman el 57\% de los temas, en el colombiano llegan al 48\%. En Colombia también tiene un peso importante los contenidos referentes al conflicto que vive el país, que se encuentran en el bloque 'Conflictos' de la Figura 2 (35\%), aquí se incluyen denuncias y violaciones a los derechos humanos.

En el bloque de la paz se incluyen los contenidos referentes a la construcción de pazy resolución de conflictos, así como los temas de seguridad, defensa y armamento y sistemas políticos e instituciones internacionales tienen más peso en el caso catalán que en el colombiano. Por otro lado, temas de derechos humanos y derechos civiles tienen más peso en la muestra colombiana.

Finalmente, en quinto lugar, los sitios Webs analizados presentan contenidos que se actualizan y se renuevan. Aunque se observa contenido que se actualiza de forma periódica: diaria, semanal, quincenal y 


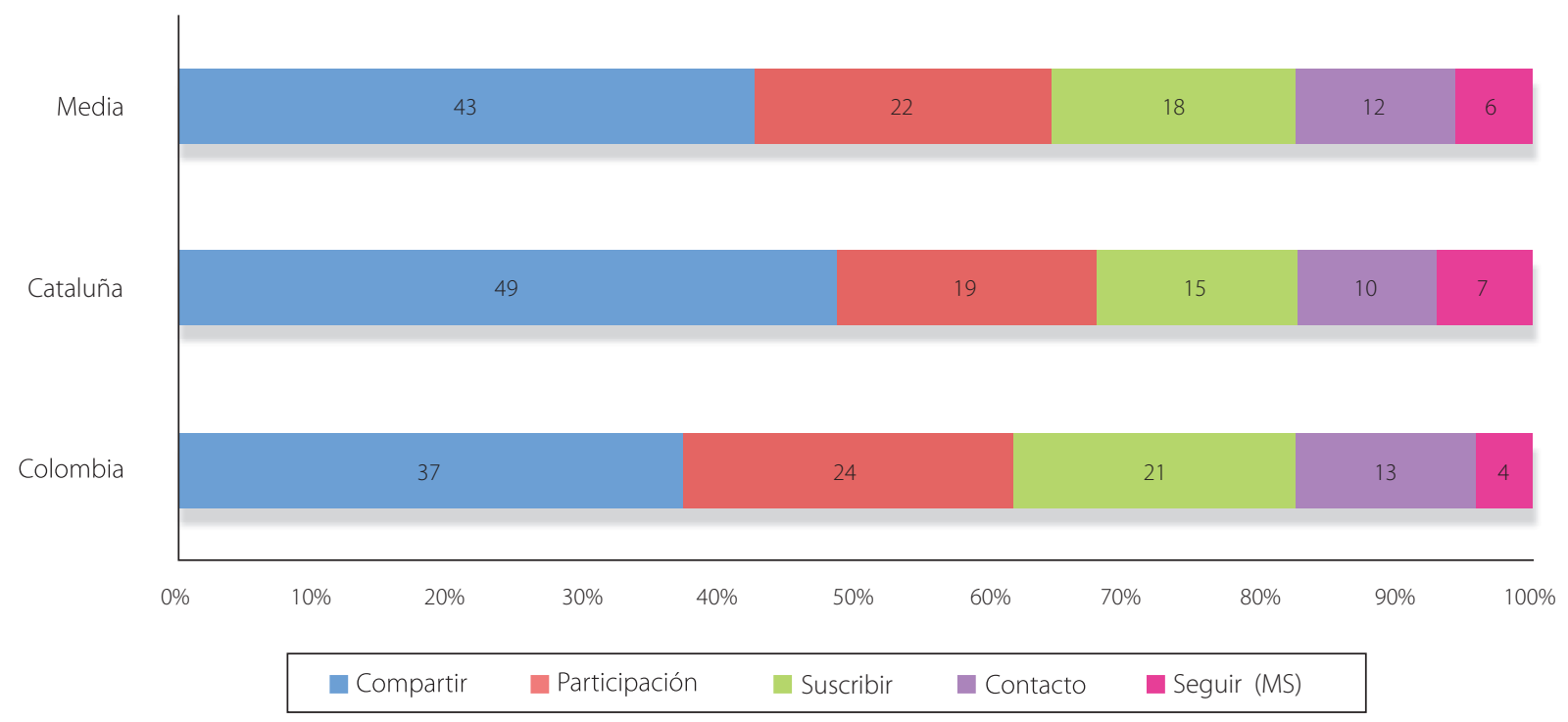

Figura 2. Porcentaje de propuestas de interacción con el usuario.

Fuente: Elaboración propia (2015 con datos de 2012).

sobretodo mensualmente, en ambos contextos destacan contenidos publicados sin una periodicidad identificada o anualmente.

Si se analizan las diferencias entre la muestra del mes de mayo y de noviembre de 2012 en ambos contextos no se observan diferencias en el 60\% de los contenidos analizados. En este periodo se han actualizado entre el 17 y el $18 \%$ de las áreas y sobre el $8 \%$ han cambiado su ubicación dentro de la página. En el caso colombiano hay un $16 \%$ de elementos nuevos por un $8 \%$ del catalán.

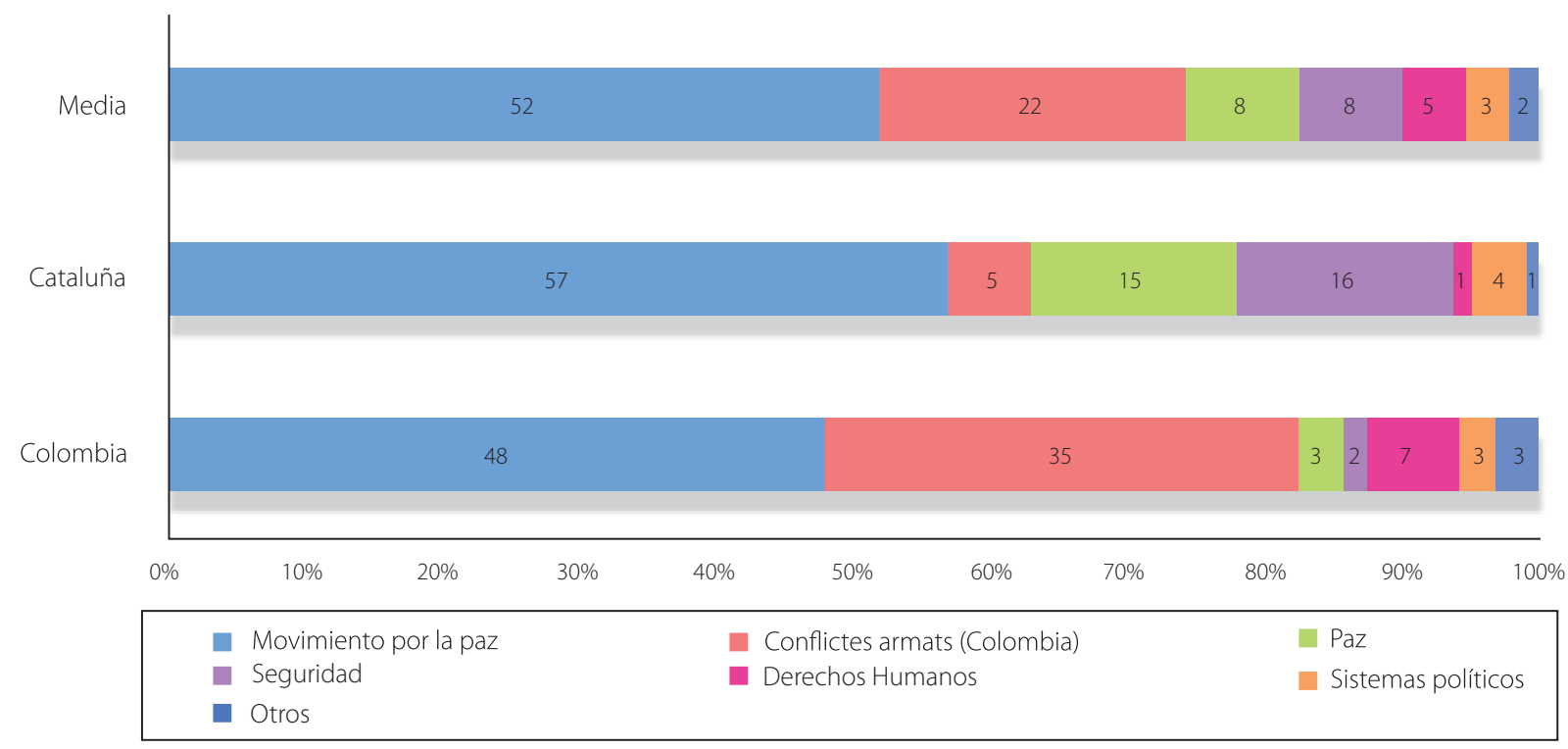

Figura 3. Porcentaje de bloques temáticos.

Fuente: Elaboración propia (2015 con datos de 2012). 
Según los responsables de comunicación de las entidades entrevistados durante el período analizado los principales motivos para modificar el sitio Web ha sido en pro de mejorar la usabilidad de la misma, adaptarse a nuevos formatos e incluir enlaces a medios sociales.

La principal problemática que presentan las Webs analizadas en ambos contextos es el acceso a la información que se aloja en ella, por este motivo las principales modificaciones del sitio se centran en su usabilidad. También se apuesta por mejorar la usabilidad de los contenidos que generan las entidades, ya que los documentos que publican acostumbran a exigir al público conocimientos previos, dedicación y atención para comprenderlos.

\section{Discusión}

Internet se ha convertido en el principal escenario comunicativo de las entidades analizadas. La actualización y el uso de la Web y los medios sociales son una realidad en el día a día de las organizaciones. En este sentido la investigación refuta la primera hipótesis: Internet juega un papel cada vez más relevante en la comunicación institucional de entidades del tercer sector.

Aunque cada vez se desarrollan más investigaciones alrededor de la actividad institucional en medios sociales, como Facebook y Twitter, y cada vez su presencia en estos espacios es más relevante (González Álvarez, 2013; Kaun, 2017). La Web se mantiene como el principal eje comunicativo de la entidad, por lo que es importante llevar a cabo investigaciones desde la comunicación institucional en este ámbito. En este sentido se refuta la segunda hipótesis de esta investigación: El sitio Web es la pieza clave en la comunicación digital de las entidades por este motivo es importante dotar a las entidades de una herramienta/técnica/mecanismo para facilitar el archivo de su sitio Web.

\section{Conclusión}

El testeo de la propuesta de análisis para sitios Web ha permitido comprobar como los aspectos propuestos permiten llevar a cabo un análisis global del sitio Web y dan respuesta a los cinco condiciones de comunicación para el cambio y la transformación social indicadas por Gumucio Dragon (2012) como se muestra a continuación:

1.Participación y apropiación: esta condición se analiza desde los aspectos de interacción y de variedad de voces. El análisis de la variedad de voces permite conocer financiación de las entidades, colaboradores y principales instituciones relacionadas.

2. Adecuación cultural y lingüística: esta condición se analiza a través del aspecto de contenido en su globalidad y de las propuestas y los elementos de interacción con los usuarios. En la apuesta para acercar los contenidos de las entidades a un público más amplio se recomienda apostar por rutas comunicativas progresivas que acerquen los contenidos a nuevos públicos y aventurarse con nuevos formatos.

3. Contenidos locales: a partir sobretodo de la actualidad y la agenda del aspecto de contenido.

4. Uso de la tecnología apropiada: adaptación de la página a sus usuarios, como se comprueba desde el elemento de análisis toda la Web del aspecto temporal.

5. Desarrollo en red: a través del amparo de voces de otros actores en las distintas secciones del sitio Web, así como de los elementos para la interacción con el resto de la red, con el análisis de la presencia de links hacia otros sitios. 
Ambos autores han participado en la autoría del artículo. En concreto S. Tejedor ha tenido un peso más importante en el concepto, revisión y aprobación final del artículo y L.M. Riu en el diseño, la revisión de bibliografía y el análisis e interpretación de los datos.

\section{Referencias}

Balas, M. La gestión de la comunicación en el tercer sector: cómo mejorar la imagen de las ONG. Madrid: Fundación ONCE/ESIC, 2011.

Bardin, L. El análisis de contenido. Madrid: Akal, 1986.

Berelson, B. Content analysis in communication research. New York: Hafner Publishing Company, 1971.

Cabalin, C. Estudiantes conectados y movilizados: el uso de Facebook en las protestas estudiantiles en Chile. Comunicar, v.XXII, n.43, p.25-33, 2014.

Cadavid Bringe, A. Los actuales debates sobre comunicación, desarrollo y cambio social. In: Cadavid Bringe, A.; Gumucio Dagron, A. (Ed.) Pensar desde la experiencia: comunicación participativa en el cambio social. Bogotá: Uniminuto, 2014. p.37-54

Callejo, J. Observación, entrevista y grupo de discusión: el silencio de tres prácticas de investigación. Revista Española de Salud Pública, v.76, n.5, p.409-422, 2002.

Casasús, J.M. Ideología y análisis de medios de comunicación. Barcelona: Mitre, 1985.

El País. Cárcel para dos periodistas por revelar afiliaciones irregulares al PP de Madrid. El Pais.com, 2009. Disponible en: http://elpais.com/diario/2009/12/24/sociedad/126160920 9_850215.html. Acceso en: 21 oct. 2018.

Fernández Viso, A. et al. Comunicación para la paz en el sector de las ONGs catalanas. Barcelona: Bretxa, 2011.

Fernández-Falero, M.R. et al. Comunicación política de los ayuntamientos a través de sus webs: caso de Extremadura. El Profesional de la Información, v.26, n.3, p.404-410, 2017.

Fuchs, C. Social media a critical introduction. London: Sage, 2014.

Galtung, J. Paz por medios pacíficos: paz y conflicto, desarrollo y civilización. Bilbao: Bakeaz, 2003.

Giraldo Luque, S.; Villegas Simón, l.; Durán Becerra, T. Uso de los sitios web de los parlamentos para promover la deliberación ciudadana en el proceso de toma de decisiones públicas: estudio comparado de diez países (América y Europa). Communication and Society, v.30, n.4, p.77-97, 2017.

González Álvarez, M.I. Las nuevas tecnologías y las redes sociales en la comunicación para la solidaridad: análisis de una campaña de sensibilización y denuncia en Twitter. Historia y Comunicación Social, v.18, n.Esp., p.689-701, 2013.

Gumucio Dagron, A. Comunicación y cambio social: raíces ideológicas y horizontes teóricos. In: Martínez Hermída, M.; Sierra Caballero, F. (Coord.). Comunicación y desarrollo: prácticas comunicativas y empoderamiento local. Barcelona: Gedisa, 2012. p.25-56.

Kaun, A. 'Our time to act has come': Desynchronization, social media time and protest movements. Media, Culture and Society, v.39, n.4, p.469-486, 2017.

Krippendorff, K. Metodología de análisis de contenido: teoría y práctica. Barcelona: Paidós, 1990.

Linchuan Qiu, J. Mobile communication and social movements. In: Downing, J.D.H. Encyclopedia social movement media. New York: Sage, 2011. p.335-338.

Lovejoy, K. Waters, R.; Saxton, G.D. Engaging stakeholders through Twitter: How nonprofit organizations are getting more out of 140 characters or less. Public Relations Review, v.38, n.2, p.313-318, 2012.

Lynch, J. Peace journalism and its discontents. Conflict and Communication Online, v.6, n.2, 2007. Available from: http:// cco.regener-online.de/2007_2/pdf/lynch.pdf. Cited: 21 oct. 2018.

Martín-Barbero, J. Oficio de cartógrafo: travesías latinoamericanas de la comunicación en la cultura. Chile: Fondo de Cultura Económica, 2002.

Marti-Pellón, D.; Craveiro, P.S.U. Exposición infantil a anuncios en webs de juegos de Brasil y de España. Comunicar, v.XXIII, n.45, p.169-177, 2015.

Moreno-Sardà, A. Rodríguez-Navas, P.M.; Corcoy Rius, M. La información de las administraciones públicas locales: las webs de los ayuntamientos de Cataluña. Revista Latina de Comunicación Social, v.68, p.502-528, 2013.

Noguera Vivo, J.M. Redes sociales como paradigma periodístico: medios españoles en Facebook. Revista Latina de Comunicación Social, v.65, p.176-186, 2010.

Papa, V. 'To activists: Please post and share your story': Renewing understandings on civic participation and the role of Facebook in the Indignados movement. European Journal of Communication, v.32, n.6, p.583- 597, 2017

Peña-López, I. Innovació social oberta: I'organització política com a plataforma. In: Costa, L.; Puntí, M. Comunicació pel canvi social. Girona: Documenta Universitària, 2014. p.59-76.

Piñeiro-Otero, T.; Costa Sánchez, C. Ciberactivismo y redes sociales: el uso de Facebook por uno de los colectivos impulsores de la 'spanish revolution', Democracia Real Ya (DRY). Observatorio Journal, n. Special, p.165-180, 2012.

Rebolledo, M.; Zamora-Medina, R.; Rodríguez-Virgili, J. Transparency in citizen participation tools and public information: A comparative study of the Spanish city councils' 
websites. El Profesional de la Información, v.26, n.3, p.361-369, 2017.

Rodríguez, C.; Gonzáles, A. Tecnologías de información y comunicación para construir lugares de no miedo: aprendiendo de la gente. Diálogos de la Comunicación, v.75, 2007. Disponible en: https://www.researchgate.net/ publication/28224804_Tecnologias_de_Informacion_y_ Comunicacion_TICs_para_Construir_Lugares_de_No_ Miedo_aprendiendo_de_la_Gente. Acceso en: 21 oct. 2018.

Rodríguez-Navas, P.M. Transparència i qualitat de la informació de les entitats sense ànim de lucre: manual i guia d'autoavaluació. Cerdanyola del Vallès: Universitat Autònoma de Barcelona, 2014.
Thelwall, M.; Cugelman, B. Monitoring Twitter strategies to discover resonating topics: The case of the UNDP. El Profesional de la Información. v.26, n.4, p.649-661, 2017

Tilly, C.; Wood, L.J. Los movimientos sociales, 1768-2008: desde sus orígenes a Facebook. Barcelona: Crítica, 2010.

Uldam, J. Social media visibility: Challenges to activism. Media, Culture and Society, v.40, n.1, p.41-58, 2017.

Vega, J. Tecnologías de la información y la comunicación, subjetividad y cambio social: una mirada a partir de algunos casos colombianos. In: Cadavid Bringe, A.; Pereira, J.M. Comunicación, desarrollo y cambio social: interrelaciones entre comunicación, movimientos ciudadanos y medios. Bogotá: Uniminuto, 2011. p.349-360. 